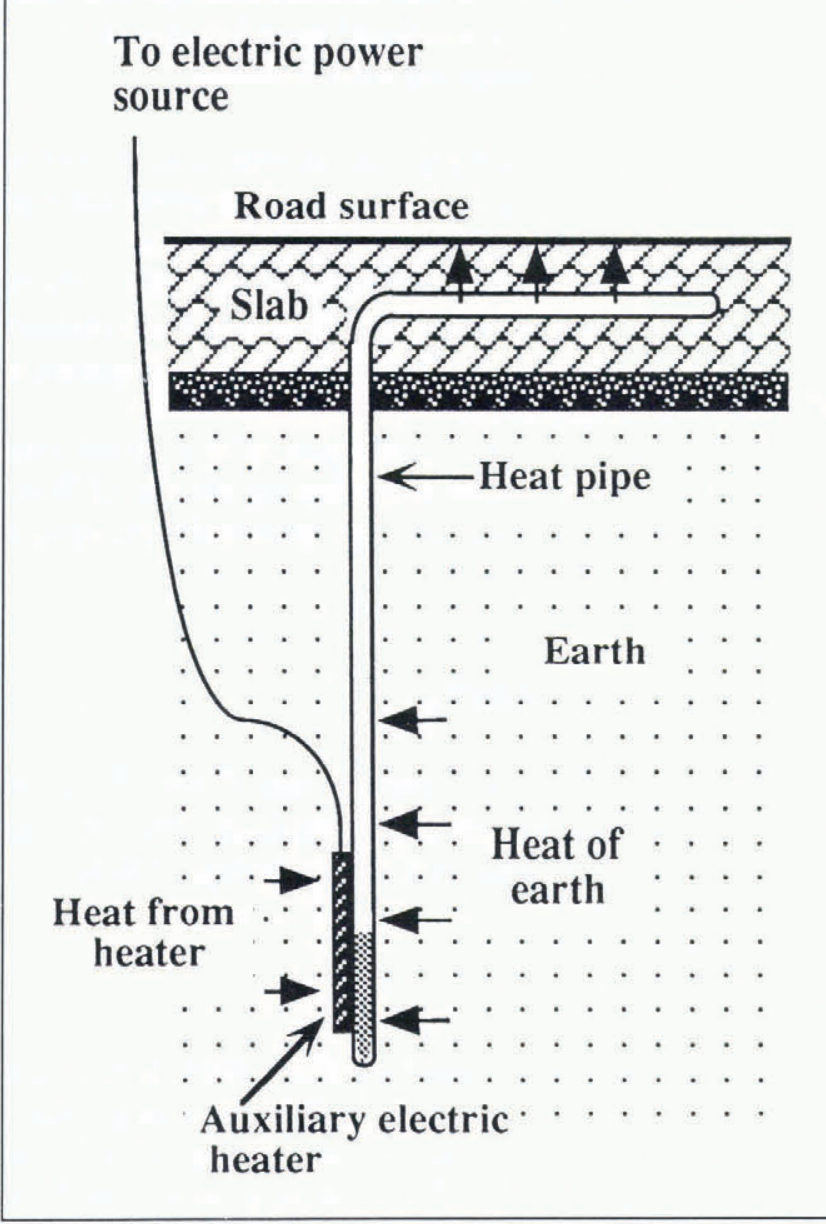

Fig. 1. Hybrid heat-pipe snow-melting system.

earth, with a length of $2 \mathrm{~m}$ remaining above the ground along the support wire. The heat pipe extracts about $10 \mathrm{~W}$ of heat from the earth at temperatures above about $6^{\circ} \mathrm{C}$ throughout the winter season, and melts the snow surrounding the support wire. A hollow space with a diameter of about five times that of the heat pipe is formed around the support wire, releasing the tension force. By this method, support wires of telephone poles can be completely protected from snow damage without further equipment or costs.

This system, using only the heat of the earth, requires no running cost. However, in cases of heavy snowfall, it is insufficient, and the cost of construction is higher than for other systems. These shortcomings are solved by a new method of hybrid heat pipe snow-melting system. The key element of the system is an auxiliary electric heater, added to the lower part of the heat pipe (see Fig. 1), which is buried vertically about $7 \mathrm{~m}$ into the earth. When snowfall is below $10 \mathrm{~cm}$ a day, this system melts snow by using only the earth's heat. On days of heavier snowfall, or extreme cold, the auxiliary heater is activated. The operating cost is several tens of times lower than that of other snow melting systems. Much of the heat source is that of the earth, so this system is very effective at melting snow in relatively small areas such as a door area, passage, small parking lot, etc.

There are many hot springs in snowy areas of Japan. In these districts as well as others, snow removal is a significant task. Waste hot spring water from hotels is used as a heat source for large-scale snow-melting systems. Exhausted waste hot spring water, at above $20^{\circ} \mathrm{C}$ even in winter, led into a ditch along a road, flows downward. The lower end of a flexible heat pipe about $1 \mathrm{~m}$ long is concreted into the bottom of the ditch to extract heat from the water flow. The remaining part of the heat pipe is installed under the road with an inclination angle of several degrees.

A very large-scale snow-melting system with low operating costs has been developed by combining a flexible long heat pipe and a boiler with burners. A Ushaped heat-exchanger jacket is attached to the lower part of the heat pipe. A heating liquid (e.g. solution of ethylene glycol or propylene glycol in water) warmed to about $40^{\circ} \mathrm{C}$ by a boiler is circulated in the jacket, transferring heat to the heat pipe. The system recently constructed in Japan has a snow melting area of $6200 \mathrm{~m}^{2}$. The operating cost of the sytem is about one third that of a system on the same scale using electric heating.

These methods will be widely used in the future, not only in Japan, but also in other countries.

\title{
Snowmelt runoff analysis using estimated distribution of snow water equivalent
}

\author{
SHigemi HatTA, \\ Department of Civil Engineering, Tomakomai College of Technology, Tomakomai, Hokkaido 059-12, Japan \\ Tosio Koike, Minjiao Lu and Norio Hayakawa \\ Department of Civil Engineering, Nagaoka University of Technology, Nagaoka, Niigata 940-21, Japan
}

\section{SUMMARY}

A snowmelt runoff model consisting of three submodels has been developed (Koike and others, 1986, 1987; Lu and others, 1989). The submodels, for estimating basinwide snow water equivalent (SWE), basin-wide snowmelt rate, and runoff, require input of the following variables: meteorological data (e.g. air temperature, insolation, 
precipitation), basin characteristics (e.g. elevation, aspect, slope), and snow-covered area (SCA). Of these, SCA is usually obtained from remote sensing data. However, use of satellite data for real-time forecasting is not always practical, because it is restricted by weather conditions and its observation cycle.

The objective of this paper is to apply the distributed snowmelt runoff model to a basin with no continuous information on SCA. The study was conducted in Takaragawa basin of the upper Tone River, Japan. The basin is $19.6 \mathrm{~km}^{2}$ in area and elevation ranges from 800 to $1960 \mathrm{~m}$ a.s.l. Air temperature, humidity, insolation, net radiation, precipitation and wind velocity were collected hourly at the basin outlet. SCA was estimated by visual inspection four times during the snowmelt season.

Initial SWE should be equal to the sum of snowmelt during the snowmelt season. Therefore, if the initial distribution of SWE is obtained, the change of SCA can be simulated by using the snowmelt model, which can express the snowmelt distribution in the basin. On the basis of this concept, we estimated the change of SCA during the snowmelt season.

First, we have to estimate the spatial distribution of SWE in the basin on the starting day of snowmelt. This can be estimated from snow-line data collected within a basin. At any point on each snow line, the net heat input is calculated from the starting day in the basin to the day of the observation, to give the initial SWE.

The initial distribution of SWE is calculated by applying this method, if the snow line is observed frequently. This is usually not the case, and interpolation between calculated SWE at "points" is necessary. In this study, the interpolation model based on the topographical features of the basin, which are elevation and distance from the bisecting line of the basin, is used.

The runoff model consists of two components, one for direct runoff, and the other for base flow. Direct runoff is generated at meshed square elements and allowed to flow down. The flow in the channel network is routed through with the kinematic wave model. Manning's law is used for the equation of motion. Channel width, roughness coefficient and separation ratio of snowmelt into two components, assumed to be constant over the basin, are determined by preliminary trial-and-error analysis. The base flow is expressed by the lumped storage-drainage model, using a low-flow fractional recession equation.

The main results obtained are as follows:

(1) In this study catchment, the distribution of SWE is approximated by a linear function of elevation and distance from the bisecting line of the basin.

(2) Using the initial distribution of snow water equivalent model and the snowmelt-distribution model, the change of SCA during snowmelt season is simulated successfully.

(3) The result of the application of the distributed snowmelt runoff model, including the simulated SCA, is in good agreement with the observed hydrograph except on rainy days.

\section{ACKNOWLEDGEMENTS}

Thanks are due to the Forestry and Forest Products Research Institute, Ministry of Agriculture, Forestry and Fishing, for providing us with the hydrological data.

\section{REFERENCES}

Koike, T., Y. Takahasi and S. Yosino. 1986. Estimation of basin-wide snow water equivalent using snowcovered area. International Association of Hydrological Sciences Publication 155 (Symposium at Budapest 1986 - Modelling Snowmelt-Induced Processes), 193-201.

Koike, T., Y. Takahasi and S. Yosino. 1987. Modelling of snowmelt distribution for the estimation of basin-wide snowmelt using snow covered area. International Association of Hydrological Sciences Publication 166 (Symposium at Vancouver 1987 - Large Scale Effects of Seasonal Snow Cover), 199-212.

Lu, M., T. Koike and N. Hayakawa. 1989. Distributed rainfall-runoff model using radar rain gauge. In Proceedings of the 33rd Japanese Conference on Hydraulics. Tokyo, Japan Society of Civil Engineers, 91-96.

The accuracy of references in the text and in this list is the responsibility of the authors, to whom queries should be addressed. 